\title{
Open Innovation Laboratory for Rapid Realisation of Sensing, Smart and Sustainable Products: Motives, Concepts and Uses in Higher Education
}

\author{
Arturo Molina ${ }^{1}$, Jhonattan Miranda ${ }^{1}$, Dante Chavarría ${ }^{1}$, Julieta Noguez ${ }^{1}$, Miguel \\ Ramírez ${ }^{1}$, Manuel E. Macías ${ }^{1}$, Edgar O. López ${ }^{1}$, Martín R. Bustamante ${ }^{1}$, Martín \\ Molina $^{1}$, Pedro Ponce ${ }^{1}$, Daniel Cortés ${ }^{1}$ and José Ramírez ${ }^{2}$ \\ ${ }^{1}$ Tecnológico de Monterrey, School of Engineering and Sciences, Mexico \\ \{armolina, jhonattan.miranda, dante.chavarria, jnoguez, miguel.ramirez, mmacias, edlopez, \\ rbustama, jose.molina, pedro.ponce, a01655708\}@itesm.mx \\ ${ }^{2}$ Instituto Tecnologico de Tlahuac, Mexico \\ pep_antonio@hotmail.com
}

\begin{abstract}
Open Innovation is not a new concept and it is been actively used by different entities to cope with new challenges posed by the evolving society in business, science and education. However, for this last one seems to be poor documentation about how higher education institutions are dealing with it. It is evident that universities are applying concepts like Open Innovation Laboratories, however it is not clear the methodologies or resources they are using. Tecnologico de Monterrey recently created its own laboratory and in this article we present the motives, concepts and uses of it in the context of higher education. Different approaches are made, from the development of core competences concepts to the physical and virtual tools used in the lab. Two study cases are briefly presented in order to illuminate how external actors are collaborating with internal actors in an Open Innovation process.
\end{abstract}

Keywords: Open Innovation, Open Innovation Lab, New Product Development, Sensing Smart and Sustainable Products, Collaborative networks, Higher Education

\section{Introduction}

The globalized world in which we live is getting increasingly competitive and there is the need to solve fast and in a novelty way the challenges that arise in business, science and education [1]. Evolution of Communication and Information Technologies (ICTs) broke geographic barriers and allowed the expansion of Collaborative Networks $(\mathrm{CN})$ and the transformation of Open Innovation (OI). The OI assumes that innovation process is an action where not only internal actors within an institution or and enterprise participate meaning that, "internal ideas can also be taken through external channels" [2]. During the last years, OI paradigm has been using especially by firms and they consider "The Open Innovation as a distributed innovation process based on purposively managed knowledge flow across 
organisational boundaries, using pecuniary and non-pecuniary mechanisms in line with the organisation's business model" [3][4].

Due to this process of OI, higher education institutions play an increasingly important role and have a closer relationship with the industry creating new research agendas [5]. In this new collaboration scheme ICTs play a fundamental part so in 2013, Tecnologico de Monterrey launched TEC21 educational model targeting a new generation of students who are digital native and demand the use of innovative learning methods and modern technological equipment. For this reason, Tecnologico de Monterrey is evolving in order to provide adequate infrastructure to face current requirements by adopting new learning methods, technologies, and redesigning its learning physical and virtual spaces. In 2017, an Open Innovation Laboratory (OIL) was established to provide innovative resources that will support the exchange of knowledge and experiences during innovation process of new product development that in its core are Sensing, Smart and Sustainable $\left(S^{3}\right)[6]$.

This paper is structured as follows. The second part is the exposition of the motives that drove the creation of this laboratory and the advantages that are obtained. In the third part it is explained the concepts in which is based including an elaboration of the three pillars that support it. Finally a brief description of the uses of the laboratory in higher education as well as some study cases for further insight of its utilization in real life scenarios.

\section{Motives}

The OIL provides the necessary tools, technological platforms and methodologies to higher education students, therefore they experiment integrated learning and collaboration skills, which in turn will provide them with the most employable profile in global professional market. These characteristics are desired worldwide thus, there are three main motives to build and implement this OIL in higher education.

(i) This OIL aims to develop desirable competencies in digital native students. Diverse researchers and institutions have defined a set of core competencies and skills [7] [8]. In this sense, product innovation research group at Tecnologico de Monterrey designed a program based on five main competencies. These competencies are named '5Cs' and they are listed below.

- Critical Thinking. Student is able to analyse, synthesise and evaluate problems in order to provide solutions. This is achieved by being involved in real scenarios where they reflect critically and are able to interpret information, and draw conclusions.

- Creativity and Innovation. Students must demonstrate originality and inventiveness in work and understand real world limits by adopting new ideas [9] and are requested to provide solutions through the development of new products.

- Communication. Improving communication skills will allow students to express ideas clearly in oral, nonverbal and written way so they will be able to participate in complex communication contexts such as negotiations, elevator pitches, and project explanation. 
- Collaboration. This competence is essential for a project development. Students must demonstrate the ability to interact and work with different actors, which participate in an OI process. Also, they assume shared responsibility for collaborative work and value the individual contributions made by each team member [10].

- Cooperation. The development of this competence allows the student to share information, knowledge and personal strengths. Cooperation is used as a strategy in group work where there are common objectives, and the success of the group performance will depend on the cooperation between the members of the team.

(ii) Provide necessary infrastructure to support professional training of students with dynamic learning experiences addressing the needs of modern learners. This includes rapid realisation platforms for rapid prototyping with physical places and virtual resources like makerspaces and remote laboratories where users can interact with internal and external communities. By doing this is possible to develop novel and innovative $\mathrm{S}^{3}$ products with high social impact on priority sectors, hence students are encouraged to promote the generation of new business models and companies' incubation.

(iii) This OIL aims to improve traditional engineering courses and to contribute to the generation and exchange of knowledge by incorporating new learning methods and design methodologies to stimulate innovation and creativity. Therefore, differences between using traditional learning methods and using the OIL in courses related to new product development (NPD) are listed in Table 1.

Table 1. Traditional courses vs. Open Innovation Laboratory

\begin{tabular}{|c|c|}
\hline Traditional Courses & Using Open Innovation Lab \\
\hline $\begin{array}{l}\text { The learning process focuses on develop } \\
\text { traditional competencies }\end{array}$ & $\begin{array}{l}\text { The learning process is aimed at developing } \\
\text { desirable competencies in the } 21 \text { st-century } \\
\text { student }\end{array}$ \\
\hline $\begin{array}{l}\text { The product development process is linear. } \\
\text { Therefore the product development process } \\
\text { is delayed }\end{array}$ & $\begin{array}{l}\text { Shorten the product development process by } \\
\text { incorporating philosophies such as Concurrent } \\
\text { Engineering (CE) }\end{array}$ \\
\hline $\begin{array}{l}\text { The product development process is carried } \\
\text { out in the classroom without specific } \\
\text { infrastructure to develop prototypes }\end{array}$ & $\begin{array}{l}\text { Provide the right tools for a rapid prototype } \\
\text { realisation }\end{array}$ \\
\hline $\begin{array}{l}\text { The course is carried out without } \\
\text { considering current social problems }\end{array}$ & $\begin{array}{l}\text { Use of specific methodologies for current social } \\
\text { problems identification }\end{array}$ \\
\hline $\begin{array}{l}\text { Solutions are proposed without reaching } \\
\text { desirable aspects of society }\end{array}$ & $\begin{array}{l}\text { Proposed solutions are based on the concept } \\
\text { 'sensing, smart and sustainable }\left(\mathrm{S}^{3}\right) \text { ' }\end{array}$ \\
\hline The problem is fictitious & Address real-life problem scenarios \\
\hline $\begin{array}{l}\text { The innovation process is close. Therefore } \\
\text { it is not considering multidisciplinary and } \\
\text { external collaborative groups }\end{array}$ & $\begin{array}{l}\text { Promote the interactive collaboration between } \\
\text { internal and external actors }\end{array}$ \\
\hline $\begin{array}{l}\text { There are no programs to monitor the } \\
\text { transfer of technology }\end{array}$ & $\begin{array}{l}\text { Support the maker movement to stimulate an } \\
\text { entrepreneurship culture and foster companies } \\
\text { incubation and economic development }\end{array}$ \\
\hline
\end{tabular}




\section{Concepts}

OIL is an arrangement of different concepts between specific knowledge and platforms hence it is necessary to structure them in a well-designed fashion. To do this the OIL is presented in three main pillars:

- Learning Techniques. Consist in an specific set of learning techniques and courses aimed to develop in students competences that are desirable to the today's engineer profile but also to aid in the propose of innovative solutions to real-life problems

- Design Methodologies. They are well developed frameworks and models used to bring structure to the ideas of products and services developed during the continuous iteration and use of the learning techniques.

- Rapid Product Realisation Platform. These modern technologies (software and hardware) are used to support the innovation process by providing the resources to design, manufacture and test the solutions obtained from the previous pillars.

Each one of the pillars of the OIL is further analysed in Table 2.

Table 2. Three major pillars of the Open Innovation Laboratory

\begin{tabular}{|c|c|}
\hline Pillars & Resources to be used \\
\hline Learning techniques & $\begin{array}{l}\text { - Active Learning } \\
\circ \quad \text { Problem-Based Learning (PBL) } \\
\circ \quad \text { Case-Based Learning (CL) } \\
\circ \quad \text { Project Oriented Learning (POL) } \\
\text { - Blended Learning } \\
\circ \quad \text { MOOCs } \\
\circ \quad \text { Online Courses } \\
\text { - Hybrid Learning } \\
\bigcirc \quad \text { Face to Face Learning } \\
\bigcirc \quad \text { Distance Learning } \\
\end{array}$ \\
\hline Design Methodologies & $\begin{array}{l}\text { - Sensing, Smart and Sustainable Product Development } \\
\text { Reference Framework }\left(S^{3}-\mathrm{RM}\right) \\
\text { - Integrated Product, Process and Manufacturing System } \\
\text { Development Reference Model (IPPMD -RM) } \\
\text { - Decision-making strategies } \\
\text { - Creative Thinking Model } \\
\text { - I-Corps } \\
\text { - Agile Software Development / Mobile Development } \\
\text { - Ontologies / Taxonomies / Process Planning Design } \\
\text { - Rapid prototyping techniques }\end{array}$ \\
\hline $\begin{array}{l}\text { Rapid Product Realisation } \\
\text { Platform }\end{array}$ & $\begin{array}{l}\text { - Makerspace (Sensing, Smart and Sustainable technologies) } \\
\text { - Reconfigurable Micro Machine Tools } \\
\text { - Micro-Factory (Fabrication of Prototypes) } \\
\text { - Artificial Intelligent Toolkit } \\
\text { - Haptics Technology } \\
\text { - Bio-Instrumentation Lab }\end{array}$ \\
\hline
\end{tabular}


- Remote Laboratories / Virtual Reality / Augmented Reality

- Robotics NAO Laboratory

- Lab on a CHIP

- Decision Centre

- PLM software platform

The OIL focuses on developing new products and services that are $\mathrm{S}^{3}$ by analysing products from the viewpoints of the sensing, smart and sustainable concepts. With these descriptions, the designers will obtain suitable information to consider during the product development process. These concepts are further explained in Table 3

Table 3. The sensing, smart and sustainable concepts

\begin{tabular}{cl}
\hline \multicolumn{1}{c}{$\mathbf{S}^{\mathbf{3}}$} & \multicolumn{1}{c}{ Description } \\
\hline Sensing & $\begin{array}{l}\text { The sensing concept refers to the capability that a system has to detect } \\
\text { events, acquire data, and measure changes that occur in a physical } \\
\text { environment [11]. }\end{array}$ \\
& $\begin{array}{l}\text { The smart concept incorporates sensing, actuation, and control functionalities } \\
\text { in order to describe and analyse situations and make decisions based on the } \\
\text { available data in a predictive or adaptive manner [12]. In addition, the } \\
\text { concept could be applied to design and enable products to work in an } \\
\text { interconnected environment and could be applied to improve decision- } \\
\text { making processes to enhance product performance. }\end{array}$ \\
& $\begin{array}{l}\text { The sustainable concept is related to design of products and manufacturing } \\
\text { processes that are ethical, as well as operationally, robust; sustainability is } \\
\text { conceived multi-dimensionally, in environmental, social and economic terms } \\
\text { [13]. }\end{array}$
\end{tabular}

\section{Uses in Higher Education}

At Tecnologico de Monterrey, OIL as a Collaborative Network has been used in different environments where external and internal actors can interact to develop new $\mathrm{S}^{3}$ products and services to support innovation process and development of high impact engineering projects. The implementation of the OIL enroll the participation of multidisciplinary professionals from universities, companies, and government as a Collaborative Network [14]. In this sense, the Collaborative Network is responsible of (Figure 1):

- Supporting knowledge generation through research stays and training programs using face-to-face courses and MOOCs (Mass On-Line Open Courses).

- Developing Research projects (e.g. new product development, manufacturing processes development and manufacturing systems development).

- Supporting technology transfer in order to generate enterprise incubation and acceleration, promote intellectual property and participate in technology testing programs. 


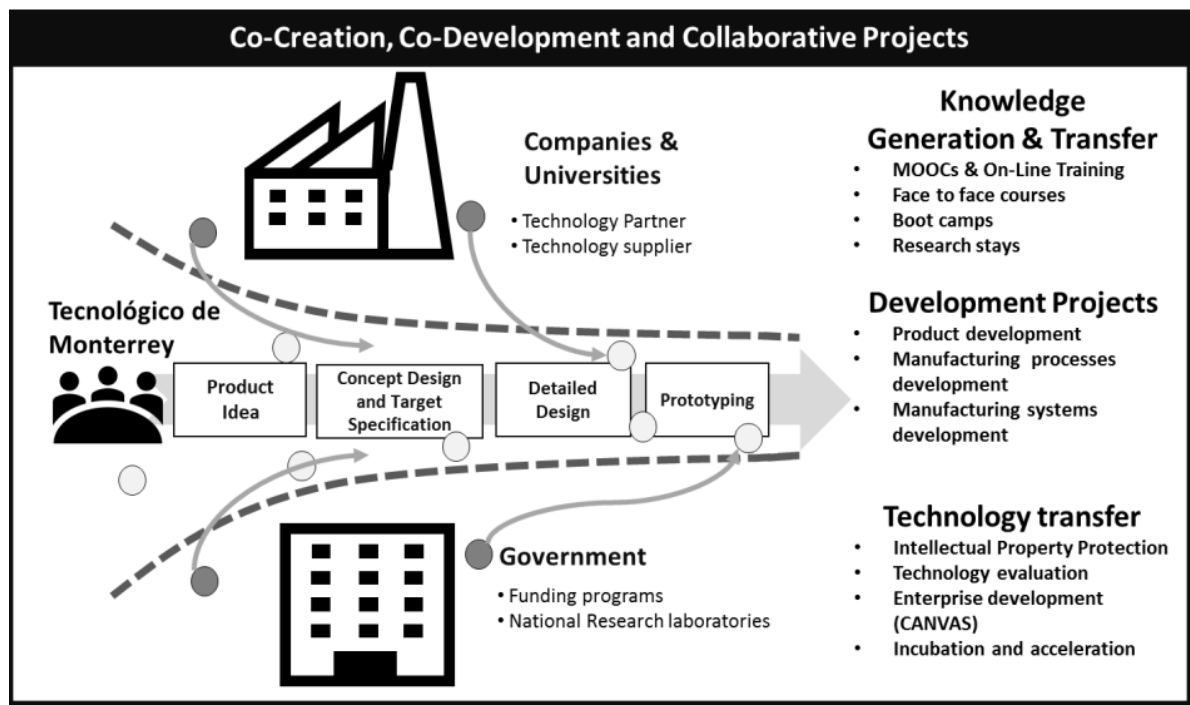

Figure 1. Open Innovation Laboratory used by companies and the government

\subsection{Case Studies}

It is important to highlight how these concepts are being applied in higher education at Tecnologico de Monterrey with the purpose of encourage its adoption in other institutions around the world thus, here are exposed 2 case studies to illustrate real life scenarios.

(i) Design Methodologies (M2017) and Integrated Manufacturing System Course where students are encouraged to develop real commercial products using methodologies like IPPMD and $\mathrm{S}^{3}$ thus, they apply different techniques, methods, thinking and engineering tools for the different product development stages during the academic period ( 16 weeks, 3 hours per week). For the materialization of the idea specific tools are provided like makerspaces, the Micro-Factory where the essential manufacturing processes for prototyping are available and different types of programs like CAD/CAM [14].

(ii) Summer research boot camp 2017 where interdisciplinary students from different universities joined efforts to solve specific problems exposed by the Product Innovation Research Group of Tecnologico de Monterrey. Teams of two people were formed and assigned a specific challenge that had to be solved through 8 weeks of research. Throughout the development of the project, different tools were employed, such as the MOOC, makerspaces where rapid prototyping technologies are available, design software to evaluate the Product Lifecycle Management (PLM) of the product and didactic resources, both physical and virtual. The results can be summarized as the enhancement of three more functions for the micro factory (Figure 2) consisting in (a) the implementation of the $3 \mathrm{~d}$ printer and laser cutter, (b) an app to learn the basics 
concepts of $\mathrm{CNC}$ with a manufacturing practice manual (c) the integration of IoT for remote health and parameters monitoring of the micromachine.

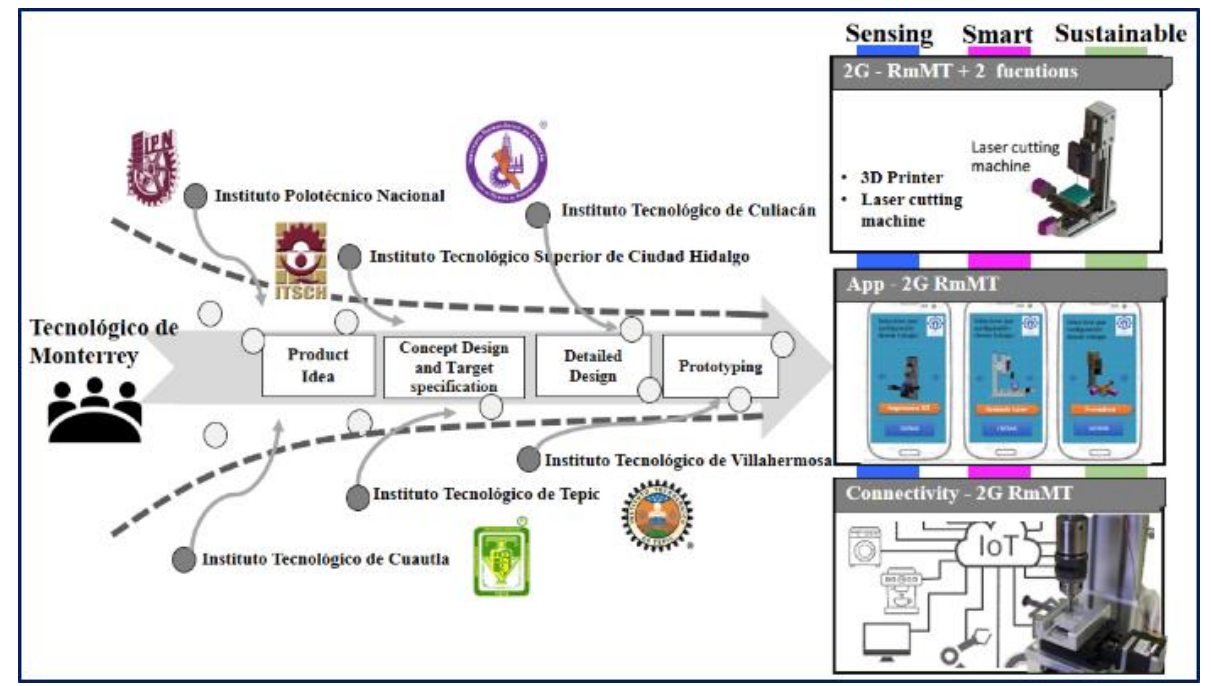

Figure 2. OI in the summer research boot camp

\section{Conclusions}

The use of Open Innovation Laboratory in higher education has provided valuable experience for students, companies and government involved in this concept of open and collaborative network approach. Several projects have materialized and are being implemented using this concept. Its use in engineering courses as well as specific projects like research summer boot camps demonstrate the development of critical skills exposed in this work by challenging the students to adapt new forms of collaboration and as a result several innovative products have passed from the divergence to the convergence of the idea and in most cases achieving the manufacturing stage. Also numerous improvements have been made to traditional courses thus, enhancing them to better suite digital natives.

Future work will focus on benchmarking learning improvements in an analytical way thus, providing hard data about the benefits of the OIL in higher education. It is also necessary to evaluate students to provide data about usability of the laboratory, suggestions and possible improvements. In addition, technologies presented will be updated, more technologies, methodologies and techniques will be proposed to be integrated in the Open Innovation Laboratory. Finally, new resources and research lines will be identified and included in order to support innovation in this space. 


\section{References}

1. L. M. Camarinha-Matos and H. Afsarmanesh, "Collaborative Networks: A New Scientific Discipline," J. Intelligent Manufacturing, vol. 16, № 4-5, pp439-452. 2005.

2. Chesbrough, H.W. 2003. "Open innovation: the new imperative for creating and profiting from technology", Harvard Business School Press.

3. Laursen, K. and A. Salter. 2006."Open for innovation: the role of openness in explaining innovation performance among UK manufacturing firms," In Strategic Management Journal, 27(2): p. 131-150.

4. Chesbrough, H.W. and M. Bogers. 2014."Explicating open innovation: clarifying an emerging paradigm for understanding innovation.” In: Chesbrough, H., Vanhaverbeke, W., West, J. (Eds.), New Frontiers in Open Innovation. Oxford University Press 2014, Oxford.

5. M. Perkmann and K. Walsh, "University-industry relationships and open innovation: Towards a research agenda," International Journal of Management Reviews, vol. 9, no. 4, pp. 259-280, 2007.

6. Miranda, J., D. Chavarría-Barrientos, M. Ramírez-Cadena, M. E. Macías, P. Ponce, J. Noguez, R. Pérez-Rodríguez, P. K. Wright, A. Molina. 2017. “Open Innovation Laboratory for Rapid Realization of Sensing, Smart and Sustainable Products (S3 Products) for Higher Education". International Journal of educational and pedagogical sciences. World Academy of Science, Engineering and Technology, Vol:11, No:5, 2017.

7. Binkley, M., Erstad, O., Herman, J., Raizen, S., Ripley, M., Miller-Ricci, M., and Rumble, M. 2012. "Defining twenty-first century skills". In P. Griffin, B. McGaw, \& E. Care (Eds.), Assessment and teaching of 21 st century skills (pp. 17-66). New York, NY: Springer.

8. Häkkinen, P., S. Järvelä, K. Mäkitalo-Siegl, A. Ahonen, P. Näykki, and T. Valtonen. 2016. "Preparing teacher-students for twenty-firstcentury learning practices (PREP 21): a framework for enhancing collaborative problem solving and strategic learning skills". $\begin{array}{lll}\text { Teachers and Teaching: theory and practice, } 2016 . & \end{array}$ http://dx.doi.org/10.1080/13540602.2016.1203772

9. Adamidi, F., Paraskeva, H. Bouta, and S. Gkemisi. 2017. "Problem-Based Learning in Language Instruction: A Collaboration and Language Learning Skills Framework in a CSCL Environment". In: Uden L., Liberona D., Liu Y. (eds) Learning Technology for Education Challenges. LTEC 2017. Communications in Computer and Information Science, vol 734. Springer, Cham.

10. Hall, P. 2005. "Interprofessional teamwork: Professional cultures as barriers". In Journal of Interprofessional Care, (2005) Supplement 1: 188 - 196

11. Porter, M. E., and J. E. Heppelmann. 2014. "How Smart, Connected Products Are Transforming Competition." in Harvard Business Review 92 (11): 64-88.

12. Nebylov, A., Sharan, S., \& Arifuddin, F. 2010. "Smart Control Systems for NextGeneration Autonomous Wing-In-Ground Effect Vehicles". IFAC Proceedings Volumes, 43(15), 112-117.

13. K. R. Haapala, F. Zhao, J. Camelio, J. W. Sutherland, S. J. Skerlos, D. A. Dornfeld, I. S. Jawahir, A. F. Clarens, and J. L. Rickli, "A Review of Engineering Research in Sustainable Manufacturing," Journal of Manufacturing Science and Engineering, vol. 135, no. 4, p. 041013, 2013.

14. Miranda, J., D. Chavarría-Barrientos, M. Macías, M. Molina, P. Ponce, P.K. Wright, A. Molina. 2017. "Experiences in interactive collaborative learning using an open innovation laboratory, the design methodologies course as case study." 2017 IEEE International Conference on Engineering, Technology and Innovation/ International Technology Management Conference (ICE/ITMC). 